\title{
CONCEPTUALIZING THE ROLE OF ORGANIZATIONAL CAPABILITIES IN ENHANCING FIRMS READINESS FOR DIGITAL BUSINESS TRANSFORMATION
}

\author{
Nabil Alkhamery \\ Faculty of Business and Management, Universiti Sultan Zainal Abidin | UniSZA, Malaysia
}

Fakhrul Anwar Zainol

Faculty of Business and Management, Universiti Sultan Zainal Abidin, Malaysia

Murad Al-Nashmi

Faculty of Business and Management, University of Science \& Technology

$-60^{\text {th }} \mathrm{Rd}$, Sana'a, Yemen

\begin{abstract}
The rapid developments in digital technologies caused digital disruption for almost all existing businesses. Digital disruption represents high threat for existing business as the new innovated services can partially or completely substitute traditional services. Many researchers agreed that incumbent firms looking to survive in the digital era should proceed with digital transformation strategy. However, many of the digital transformation initiatives fail to meet organizations ambitions. Scholars referred this failure to the ignoring of the development of the capabilities on which the planning and execution of digital transformation depend. The lack of understanding process of digital transformation motivated the researcher to conduct this study aiming to examine the role of organizational capabilities in improving firm's readiness for a successful digital transformation process. The researcher will empirically validate a proposed model for digital transformation readiness. The 260sample size will constitute of mid-level employees in telecommunication firms in Yemen who will answer the study questionnaire. The collected data will be analyzed with Structure Equation Modeling (SEM) method. The proposed model that represents new contribution in knowledge body of digital transformation will assist managers to assess their firm's readiness for the digital transformation and the researcher recommends to conducts further studies to extend this model to incorporate more factors.
\end{abstract}

Key words: Disruption; Digital; Transformation; Dynamic; Readiness; Capabilities. 
Cite this Article: Nabil Alkhamery, Fakhrul Anwar Zainol and Murad Al-Nashmi, Conceptualizing the Role of Organizational Capabilities in Enhancing Firms Readiness for Digital Business Transformation, International Journal of Management, 11(12), 2020, pp 785-797.

http://iaeme.com/Home/issue/IJM?Volume=11\&Issue=12

\section{INTRODUCTION}

The rapid developments in digital technologies caused what becomes known as digital disruption that represents high threat for existing business in different industries. Digital disruption occurred when new entrants used the digital technologies in offering new innovated services that can partially or completely substitute traditional services. Roger (2016) described the change result by the digital technologies by the digital revolution that has dramatically changed the old business rules and concepts. The new digital products and services have changed the market structure and the rules of competition that moved the firms to completely different competitive opportunities and risks (Porter \& Heppelmann, 2014). Many startups such as Facebook, Uber, Amazon, Airbnb and others as per (Sanchez, 2017) have been admired with their abilities to define successful business models based on innovative use of digital technologies and they are now disrupting the traditional businesses of many industries. The disruption made by those startups has impacted the strategies of many industries including transportation, telecommunication, accommodation, manufacturing and many all other industries (Stewart, Schatz, \& Khare, 2017, Shrivastava, 2017, Karimi \& Walter, 2015). As per a survey conducted by (Hoberg et al., 2015), more than $38 \%$ of executives believe that their company's business model to be threatened by digitalization. Telecommunication industry among industries got disruption by digital services or what become known as Over The Top (OTT) services, such as Skype, WhatsApp, Imo and other services that can substitute the traditional telecommunication services (Onyeji-Nwogu et. al, 2017). The researcher conducted a pre-study survey with 16 telecom senior managers in Yemen. The researcher found that $68 \%$ of respondents believed agreed that OTT services have disrupted their Strategies. Furthermore, more than $74 \%$ of them admitted that their revenue was affected negatively by the OTT services and $80 \%$ agreed on the importance of proceeding with new strategies to reduce this effect of the faced disruption and to enable them to respond to such disruptive services to keep competitive in the market. As per (Mihardjo \& Sasmoko, 2019), telecommunication firms have no choice than transforming their services in new way so that to minimize the gap in business model innovations and develop new distinguished digital capabilities. Kotarba, (2018) defined digital transformation as the redesign of business models with the effective use of digital technologies and innovation that trigger changes in consumer and social behaviours. Due to its importance to respond to digital disruption that pre-digital firms faced, digital transformation becomes a hot topic among scholars and partitions. Despite this focus on digital transformation, as per Nwaiwu (2018), there is still no consensus on a framework for digital transformation that can assist scholars and practitioners better understand the process to achieve digital business transformation objectives within a firm. Few managers who consider digital transformation is an easy process to implement (Afandi, 2017). According to Fitzgerald et al. (2013), most companies actually struggle to achieve the full benefits from this process. Many Scholars as per (Orji, 2019, Afandi, 2017; Sow \& Aborbie, 2018; Mihardjo \& Sasmoko, 2019 ) referred these difficulties to the absence of required capabilities to use technology and the ignoring of the development of the skills and capabilities that digital transformation depends. Hence there is a need for frameworks that describe the preparedness of firms for digital transformation which represent a justified gap that triggered for this study. The researcher is examining the role of leadership 
and culture values in improving firm's readiness for digital transformation. In addition, the researcher also interested in identify a possible mediation role for dynamic capabilities in reconfiguring operational capabilities to enhance organizational readiness of firms for digital transformation. The outcome of the study will represent a significant contribution in the body of knowledge of the digital transformation strategy.

\section{LITERATURE REVIEW}

Although the digital transformation (DT or DX) is getting more popular topic recently, the ideas of digital products and services have been referred in literature since the 1990s and 2000s. Recently with the development of new disruptive services that effect many industries, the digital transformation strategy become a hot topic in both academic and practical fields. The technological development becomes a source of competitive advantages (Packmohr, Mosconi, Santa-Eulalia, 2020; Majid et al., 2020). Many Scholars focused on drivers and opportunities of digital transformation and many of them tried to conceptualize the digital transformation phenomenon. Nevertheless, there is still lack of holistic view of digital transformation that can answer all aspect in relation to digital transformation strategy Nwaiwu (2018). In particular the readiness of firms for digital transformation that is being addressed in this study. The researcher focuses in this study the association relationship between operational capabilities and the firm's organizational readiness for digital transformation.

\section{ORGANIZATIONAL READINESS FOR DIGITAL TRANSFORMATION}

The readiness for change term is historic business term used by scholars in different areas of study with different level of focus. The readiness for change in an organization as per (Albano, 2010) is defined as the level to which people are prepared to contribute in organizational development practices. The readiness assessment is needed when there is a major change to take place within an organization. Organizational readiness was described by (Weiner, 2009) as shared organizational members change commitment and belief in their collective capability to perform that change. The concept of organizational readiness is widely considered as a critical prerequisite to the successful adoption of organizational change (Albano, 2010). Two approaches to explain organizational readiness were found in literature. The first approach considers the psychological state of organizational team in respect to certain organizational change (Armenakis et al., 1993). Organizational readiness as per this approach can be shown in organizational individuals' beliefs, attitudes, and intentions regarding the level to which changes are required or Change Commitment, and the organization's ability to make those changes or Change efficacy (Albano, 2010; Dalila et al., 2020). The second approach characterized by the professional view was developed by Campbell et al. (2001) who suggested six dimensions of eHealth readiness in connection with the professional preparedness to change (turf, efficacy, practice context, apprehension, time to learn and ownership). Based on both approaches, Albano (2010) developed a model consists of three components that have been recognized as relevant in the assessment of the overall organizational readiness for the adoption of Electronic Health Record Systems (EHR-S): the innovation-oriented climate, the information maturity and the cooperation maturity. To trigger a change toward the target that leaders determine, conflicts views must be resolved so that organizational members beliefs and cognitions match with leaders views and this confirms that a state of readiness must be created (Armenakis et al., 1993). In this research, the researcher needs to measure the readiness of organizational firms to proceed with this fundamental change that effect all business process and operation. Hence the researcher 
decided to embrace Weiner, (2009) framework to measure organizational readiness construct with the two components; Change Commitment and Change efficacy.

\section{LEADERSHIP}

Leadership is a topic that continuously attracting attention of scholars since long time ago to present. The researcher refers in this section to couple of early and recent views on leadership as found in literature and different theories that have been developed to explain what leadership is and whether it is made or bought as well as its role in firm performance. Leadership has been understood in terms of individual traits, behaviour, influence over other people (Yukl, 2013). This is why there is no single definition for leadership as each definition is related to its background theory. Koontz, O'Donnell and Weihrich (1984) defined leadership as the capacity to exert interpersonal influence by means of communication towards the attainment of a desired end. As per (DeRue \& Ashford, 2010), five essential components that define leadership including leaders - followers, influence, organizational targets, people, and change.

Different theories in related to leadership have been found in literature such as gREAT MAN THEORY, TRAIT THEORY, BEHAVIOURAL THEORIES, CONTINGENCY THEORIES, TRANSACTION THEORIES AND TRANSFORMATIONAL THEORIES. THE GREAT MAN theory developed by Dowd on 1936 implicit that great leaders are innate and not made (Madanchian et al., 2016). The concept of this theory was extended in Trait theory. Trait theory explains leadership as individuals born specific traits that make them good leaders which also support the view of leadership as natural but not made (Madanchian et al., 2016).

Researchers support this thought developed range of traits that they argue that are reasons for successful leadership (JW Fleenor, 2006). Examples of characteristics considered as traits of effective leaders include: self-confidence, intelligence, strategic focus, energy, decision makers, knowledge, tolerance of stress, determine when facing problems and resultorientation (Yukl 1989; Northouse 2015; Yukl 2011) as cited by (Madanchian et al., 2016). This thought is not supported by many other researchers who see no difference between leader and followers in respect to their leadership characteristics (Fleenor, 2006). Hence the thought of leadership as new situational approaches is being introduced which involve behavioural theories of leadership. Leadership has been then viewed as a social process that takes place in a group context in which the leader influences behaviours of people to achieve the organizational goals (Oke et al., 2009). The behavioural approach enables to determine and measure related leadership actions and behavioural styles that lead to successful leadership results, such as morale and productivity (Oelofse, 2007). Stogdill expected that effective leadership is determined by situation and the leader's personal traits (Madanchian et al., 2016). The required behaviours for leader's role as an influencer may vary between being inspirational, motivational and visionary to a role which involves the development of suitable organizational context (Oke et al., 2009). Bass and Avolio, (1993) referred to these as transformational and transactional leadership styles. Leadership styles are very important for firms and can lead to achieve the goals so that when a firm change is needed, the matching leadership style may put this change easy to implement. However, the leadership capabilities shall not be constant skills and shall continue to be modified as needed. The rapid development in technologies and the introducing the new digital technologies that put more pressure on leaders in firms to adapt themselves and their skills with digital capabilities so that they can protect their business against the digital disruption faced. The failure of many firms in the digital era or industry 4.0 can be possibly referred to the lack of proper leadership capabilities that were supposed to enable them to adapt their strategies and their firm's operations, resources, and business process with the continuously changing environment. KODAK has struggled to keep up with the competitors who were quicker to adapt to digital 
era. Once of the possible reasons for KODAK failure was the lack of suitable leadership skills that can quickly understand the trend of the new market and can quickly adapt their firms with the new market requirements as justified (Wade et al., 2011). As the market keeps changing, the skills of leaders also have to be adapted to this change. Incumbents firms that fail in the digital era seems failed to develop digital capabilities including the leadership capabilities that can set a digital vision and execute on it (Westerman, Bonnet and Mcafee, 2014). Many studies found that most of organizational constraints such as lack of urgency, unclear vision, unaligned strategies could be addressed through effective leadership (Afandi, 2017). Toduk and Gande (2016) proposed four competencies that describes the digital leader and that include: (1) creative, (2) deep knowledge (3) strong networking and collaboration, and (4) loyal participation via vision. In this study, the role of digital leadership will be identified according to the following hypotheses:

H1: Digital Leadership (DL) has positive impact on dynamic capabilities development

H2: Digital Leadership (DL), is being mediated by Dynamic Capabilities (DC) with Organizational Readiness for Digital Transformation (ORDT).

\section{ORGANIZATIONAL CULTURE}

Culture comprises the values and characteristics set of behaviour that define how things get done in an organization and determine the way employees interact with each other ( Shin et al., 2012 , Hemerling et al., 2018). Organizational culture has been known as the main influential factor in investigation of organizations in various contexts, including its role in creating competitive and collaborative advantages, and its effect on firm's long-term performance (Zhang \& Li, 2016). Organizational values have impact on the firm's strategic orientation in terms of sensing or exploitation (Matzler et al., 2013). The role of culture becomes more important in the dynamic environments as it requires a team with an open mindset, easy to adapt and accept to change. This is why culture values shall be supportive for digital transformation. Many scholars agreed that culture fundamentally impacts the success of business transformations (Hartl \& Hess, 2017). A proposition developed by Venkatraman (1994)'s as cited by (Parida et al., 2016) that condition the full exploitation of IT deployment benefit by organizational and culture transformation. Based on this proposition, Fitzgerald et al. (2013) argues that the establishment of a digital mindset and a change of culture is essential success factor for digital transformation. Migration into digital is not only concern with introducing new technology, but it is about conducting changes in business process, people and business models (Haddud \& McAllen, 2018). Many digital transformation initiatives experience some failures due to unsupported culture that prevents change as found by (Hartl \& Hess, 2017). A possible approach to avoid the failure in digital transformation is to embrace couple of organizational and cultural values that enhance the internal environment readiness for the innovation and change (Albano, 2010). Many studies focused on the role of culture in organizations change and most of those studies emphasized the important role of culture in any organizational change to improve the performance or adopting new ways to do things. As digital transformation changes everything in an organization including process, people, strategies, operations and business models, the changing of culture and building new digital-based culture vales is fundamental step to secure the success for the digital transformation strategies. A research conducted by Kane et al., (2015) referred to the assumption that organizational culture is critically essential to effectively achieve all benefits of digital technologies in the workplace (Mukhtar et al., 2020). The missing of supportive organizational culture is one of the main challenges to firm's success in the digital age as found by Goran et al., (2017). McKinsey's 2017 recent survey of global executives showed that culture is the most noticeable self-reported preventor to digital effectiveness. Many 
studies that focused on digital transformation readiness found that culture does have association with digital transformation readiness (Gill, M, Shar, VanBoskirk, 2016; Afthanorhan, Foziah, \& Majid, 2020; Schumacher, A., Erol, S., Sihn, W. 2016, Goran et al., 2017; Hartl \& Hess, 2017; Hemerling et al., 2018; Hogan \& Coote, 2014)). The culture also influences other organizational capabilities such as dynamic capabilities (Hogan \& Coote, 2014; Pérez López et al., 2004). The researcher in this study is examining the role of Organizational culture in digital transformation readiness with the following hypotheses:

H3: Organizational culture (OC) has positive impact on Dynamic Capabilities (DC) development

H4: Organizational culture (OC), mediated by Dynamic Capabilities (DC) positively associated with Organizational Readiness for Digital Transformation (ORDT).

\section{DYNAMIC CAPABILITIES}

Dynamic capabilities approach was developed to explain the reasons of why some firms are more successful than others in maintaining competitive advantages in dynamic markets. Dynamic capabilities are sometimes called the first-order capabilities as they refer to capabilities that are needed in a turbulent environment in contrast with organizational zeroorder capabilities that refer to how an organization doing business in fixed markets (Winter, 2003). There is a growing attention by scholars on the role of dynamic capabilities in organizational performance especially in the turbulent global environments (Miles,2012; Nasir et al., 2020). They think that the operational capabilities are not sufficient to maintain competitive advantage in dynamic and unpredictable changing market (Eisenhardt and Martin, 2000; Teece et al., 1997) as cited by (Wu, 2010). Hence those researchers argue that dynamic capabilities are essential in learning competitive advantage under turbulent markets. As markets shift from a fixed competitive environment to a Schumpeterian competitive environment characterized by dynamic competition, rapid technological change, principles of organizational competition have changed significantly (Teece, 2013; Schumpeter, 1911) as cited by McLaughlin, (2017). In order to stay competitive, firms have to adopt and integrate technology into their operating processes as well as they have to change the way they deal with technology (Wade et al., 2011). Dynamic capabilities were defined by (Teece et al., 1997), as the firm's ability to integrate, build, and reconfigure internal and external competences to address rapid changing environments. Dynamic capabilities are being looked by many authors as ambiguous concept (winter,2003). Although this limitation in understanding dynamic capabilities concept, there is a significant agreement among scholars that dynamic capabilities comparing with ordinary are related to change. Dynamic capabilities enable organizations to renew their competences to meet changing market requirements $(\mathrm{Wu}$, 2010). This study will investigate the role of dynamic capabilities to reconfigure operational capabilities to enable firms to respond to digital disruptors in a way to protect their competitive position in the market.

It should be also important to mention that there is still no consensus on the conceptualization of dynamic capabilities components and how these capabilities can be developed. Hence this research will contribute in filling this theoretical gap by providing some empirical evidence on dynamic capabilities components development. The researcher found few studies where authors tried to conceptualize dynamic capabilities components for the purpose of measuring dynamic capabilities in a firm. One approach to conceptualize dynamic capability proposed by (Wang \& Ahmed, 2007) and used by (Parida et al., 2016) where four related, but distinctive sub-capabilities were suggested to constitute the dynamic capabilities: absorptive capability, adaptive capability, innovation capability, and network capability. Lin and $\mathrm{Wu}$ (2014) divided the dynamic capabilities into three different sub- 
capabilities which are: Integration capability, Learning capability and reconfiguration capability. However researcher will use a conceptualization of dynamic capabilities suggested by Pavlou and El Sawy (2011) where they proposed a set of identifiable and specific components including: (i) sensing; (ii) learning, (iii) integration, and (iv) coordination capabilities. As per the (Pavlou \& El Sawy, 2011) the proposed dynamic capabilities are neither exhaustive, nor sufficient for reconfiguration to occur, but they are assumed as important enablers of the ability to reconfigure operational capabilities. The suggested four components are describing the reconfiguration task done by dynamic capabilities for the operational capabilities as Figure 1 In the context of digital transformation, these components shall enhance firm readiness for digital transformation and hence improve firm capability to respond to the digital disruption previously explained.

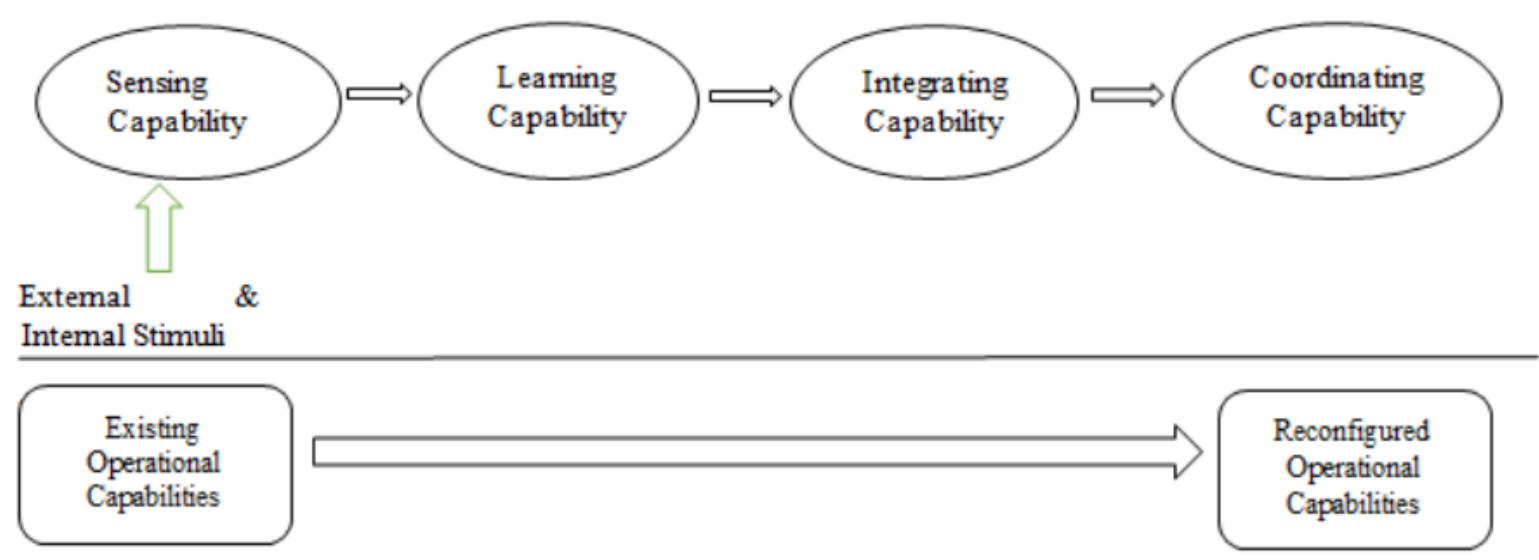

Figure 1 Conceptual Framework for Reconfiguring Operational Capabilities with Dynamic Capabilities (source: (Pavlou \& El Sawy, 2011))

The researcher found few studies (Karimi \& Walter, 2015, Carcary, et al., 2015) that confirmed the association between dynamic capabilities and digital transformation success. Lin and $\mathrm{Wu}$ (2014) also examined the mediation role of dynamic capabilities between RBVbased resources and firm's performance. In this study the researcher is examining the mediation role of dynamic capabilities between the leadership, culture from one side and organization readiness for digital transformation. Hence the following hypotheses will be examined:

H5: Dynamic Capabilities (DC) has positive impact on Organizational Readiness for Digital Transformation (ORDT).

H6: Dynamic Capabilities (DC), mediate the relationship between Digital Leadership (DL), Organizational culture (OC) from one side and Organizational Readiness for Digital Transformation (ORDT) from other side.

\section{UNDERLYING THEORIES}

Resources Based View (RBV) considers internal resources and capabilities of a firm as the main reasons for the superior performance and shall secure the competitiveness advantage for firm over its competitors. Few scholars (Koch and Windsperger, 2017) argue that RBV perspectives are only related to assumptions of pre-digital environment. The Researcher supports the thought of other scholars ( Parida et al., 2016; Nwankpa \& Roumani, 2016; Marisa Analia Sanchez, 2017;) who applied the RBV framework in the context of digital transformation and consider dynamic capabilities as extension for RBV in the digital environment. Those scholars argue that dynamic capabilities is built on the RBV in realizing 
the importance of continual modification and adaption of capabilities in accordance with changing in external forces (Mikalef \& Pateli, 2017; Reilly \& Pamela Sharkey Scott, 2009; Zaidi \& Othman, 2012). The view of dynamic capabilities was early coined by Teece, (1990) to explain how firms integrate, build, and reconfigure their internal and external firm-specific capabilities into new capabilities that match with the dynamic environment. In other words, it is to assist firms to sustain a competitive advantage in the changing environments (Teece, 2007). Wu, (2010) examined the mediation role of dynamic capabilities between RBV resources and firm performance.

\section{THE CONCEPTUAL FRAMEWORK}

Based on the Resources Based value theory (RBV), Dynamic capabilities approach (DCA), the researcher is proposing a new model that can be used to assess organizational readiness of firms for digital transformation as shown in figure 2 below. The developed model will be empirically tested throughout this study. While the selection of dynamic capabilities come from the intention of the researcher to identify the possible mediation role of dynamic capabilities in reconfiguring operational capabilities to adapt them with the volatile environment such as what is caused by digital disruption as explained by (Teece et al., 1997). This role for dynamic capabilities was confirmed by Lin and Wu (2014) who found a mediation role between valuable, rare, inimitable and non-substitutable (VRIN) resources with firm performance so the researcher is examining this mediation role of dynamic capacities in the context of digital transformation readiness.

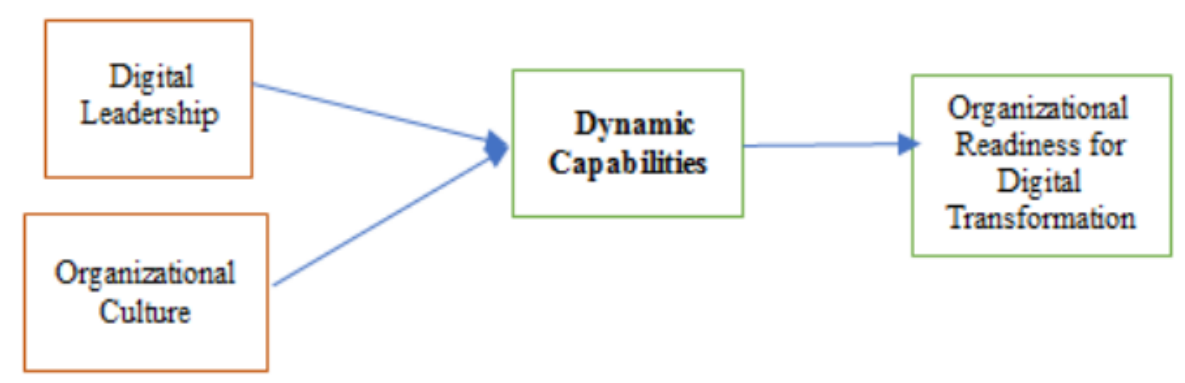

Figure 2 Research Conceptual Framework

\section{CONCLUSION}

The proposed model will be a significant contribution to the body of knowledge in relation to digital transformation. This model will also emphasize the importance of dynamic capabilities role in digital era as capabilities that help firms to respond to digital disruption. The model from the other hand will assist managers to assess their firms against readiness for digital transformation and identify any gaps in terms of organizational capabilities and skills to be addressed. This model still needs to be extended in future studies to include other technological and environmental factors that have impact on firm's readiness for digital transformation. It is also recommended to examine this model in other industries with different environment conditions. 


\section{REFERENCES}

[1] Aboelmaged, M. G. (2014), "Predicting e-readiness at firm-level: An analysis of technological, organizational and environmental (TOE) effects on e-maintenance readiness in manufacturing firms", International Journal of Information Management,34 (5), 639-651.

[2] Afandi, W. (2017), "The role of strategic leadership in digital transformation process", IJRRAS, 33, (2), 19-22.

[3] Afthanorhan, A., Foziah, H., \& Majid, N. A. (2020). Investigating digital library success using the DeLone and McLean information system success 2.0: The analysis of common factor based structural equation modeling. Paper presented at the Journal of Physics: Conference Series, , 1529(4) doi:10.1088/1742-6596/1529/4/042052

[4] Albano, V. (2010), "Organizational Readiness and Success of the EHR-S Adoption", Management of the Interconnected World (pp. 145-152). 7908-2404-9_18

[5] Amit, R. and Schoemaker, P.J. (1993), "Strategic Assets and Organizational Rent", Strategic Management Journal, 14: 33-46.

[6] Armenakis, A. A., Harris, S. G., \& Mossholder, K. W. (1993), "Creating Readiness for Organizational Change", Human Relations, 46(6), 681-703.

[7] Awa, H. O., Ukoha, O., \& Emecheta, B. C. (2016), "Using T-O-E theoretical framework to study the adoption of ERP solution", Cogent Business \& Management, 3(1), 1-23.

[8] Barney, (1991), "Firms Resources and Sustained Competitive Advantage", Emerlad Group Publishing Limited. Advances in Strategic Management, Volume 17 Pages 203-227.

[9] Bass, B. M., \& Avolio, B. J. (1994), "Transformational Leadership and Organizational Culture", International Journal of Public Administration, 17(3-4), 541-554.

[10] Bharadwaj, A. S. (2000), "A Resource-Based Perspective on Information Technology Capability and Firm Performance: An Empirical Investigation", MIS Quarterly, 24,(1), 169.

[11] Campbell JD et al (2001), "Introducing telemedicine technology to rural physicians and setting", J Family Pract 50 (5), 419-424.

[12] Dalila, D., Latif, H., Jaafar, N., Aziz, I., \& Afthanorhan, A. (2020). The mediating effect of personal values on the relationships between attitudes, subjective norms, perceived behavioral control and intention to use. Management Science Letters, 10(1), 153-162.

[13] Deetz, S. A., Tracy, S. J., \& Simpson, J. L. (2000), "Leading organizations through transitions: Communication and cultural change. London, SAGE Publications, Newbury Park, California

[14] DeRue, D., \& Ashford, S. (2010), "Who will lead and who will follow? Social process of leadership identity construction in organizations", Academy of Management Review, 35(4), $627-647$.

[15] Downes, Nunes. (2014), "Big Bang Disruption: Strategy in the Age of Devastating Innovation", Portfolio Hardcover.

[16] Fleenor (2006), "Trait Approach to Leadership", Publisher: Sage, Newbury Park, California

[17] Fitzgerald, M., Kruschwitz, N., Bonnet, D., and Welch, M. (2014). "Embracing Digital Technology: A New Strategic Imperative", MIT Sloan Management Review (55:2), pp. 1-12.

[18] Gill, M., VanBoskirk, S.: The Digital Maturity Model 4.0. Benchmarks: Digital business transformation playbook (2016). https://forrester.nitro-digital.com/pdf/Forresters\%20Digital\%20Maturity\%20Model\%204.0.pdf. accessed on 29/6/2020.

[19] Goran, J., LaBerge, L., \& Srinivasan, R. (2017), "Culture for a digital age" McKinsy Quarterly, $1-10$. 
[20] Haddud, A., \& McAllen, D. (2018), "Digital Workplace Management: Exploring Aspects Related to Culture, Innovation, and Leadership", Portland International Conference on Management of Engineering and Technology (PICMET), 1-6.

[21] Hartl, E., \& Hess, T. (2017), "The Role of Cultural Values for Digital Transformation: Insights from a Delphi Study", Conference: Proceedings of the 23rd Americas Conference on Information Systems (AMCIS 2017), At: Boston, USA

[22] Hemerling, J., Kilmann, J., Danoesastro, M., Stutts, L., \& Ahern, C. (2018), "It's Not a Digital Transformation without a Digital Culture" Consulting Group, https://www.bcg.com/publications/2018/not-digital-transformation-without-digitalculture.aspx, accessed on 26/6/2020.

[23] Hoberg et al. (2015). Skills for Digital Transformation. Research Report 2015.

[24] Hogan, S. J. \& Coote, L. V. (2014). Organizational culture, innovation and performance: A test of Schein's Model. Journal of Business Research, Vol. 67, p. 1609-1621.

[25] Karimi, J., \& Walter, Z. (2015), "The Role of Dynamic Capabilities in Responding to Digital Disruption: A Factor-Based Study of the Newspaper Industry", Journal of Management Information Systems, 32(1), 39-81

[26] Kane, g. C., palmer, d., phillips, a. N., \& kiron, d. (2015), "is your business ready for a digital future? Business transformation", business transformation, 56(4), 36-45.

[27] Koch, T., \& Windsperger, J. (2017), "Seeing through the network: Competitive advantage in the digital economy", Journal of Organization Design, 6(1), 6.

[28] Koontz, H., O’Donnell, C., Weihrich, H., 1984, "Management", McGraw-Hill, Singapore. P661.

[29] Kotarba, M. (2018), "Digital Transformation of Business Models", Foundations of Management, 10(1), 123-142.

[30] Larjovuori, R.-L., Bordi, L., \& Heikkilä-Tammi, K. (2018), "Leadership in the digital business transformation", Proceedings of the 22nd International Academic Mindtrek Conference on Mindtrek '18, 212-221.

[31] Leung, D., Lo, A., Fong, L. H. N., \& Law, R. (2015), "Applying the Technology-OrganizationEnvironment framework to explore ICT initial and continued adoption: An exploratory study of an independent hotel in Hong Kong", Tourism Recreation Research, 40(3), 391-406

[32] Lin, Y., \& Wu, L.-Y. (2014), "Exploring the role of dynamic capabilities in firm performance under the resource-based view framework", Journal of Business Research, 67(3), 407-413.

[33] Majid, N. A., Zainol, F. A., Afthanorhan, A., Yusoff, A. S. M., Rahim, B. H. A., Ismail, N. A., Rahman, N. A. A. (2020). What triggers entrepreneurial intention among young generation? the impact of social media. Paper presented at the Journal of Physics: Conference Series, , 1529(4) doi:10.1088/1742-6596/1529/4/042066

[34] Mukhtar, N. D., Afthanorhan, A., Ghazali, P. L., \& Foziah, H. (2020). A conceptual paper for self-service technology (sst) on grabcar users. Humanities and Social Sciences Reviews, 8(2), 569-578. doi:10.18510/hssr.2020.8265

[35] Madanchian, M., Hussein, N., Noordin, F., \& Taherdoost, H. (2016), "Leadership Theories; an Overview of Early Stages", Recent Advances in Energy, Environment and Financial Science 5, 198-201.

[36] Matzler, K., Abfalter, D. E., Mooradian, T. A., \& Bailom, F. (2013), "Corporate culture as an antecedent of successful exploration and exploitation", International Journal of Innovation Management, 17(05), 1-23.

[37] McLaughlin, S. A. (2017). Dynamic capabilities: Taking an emerging technology perspective. International Journal of Manufacturing Technology and Management, 31(1/2/3), 62. 
[38] Mihardjo, Sasmoko, Alamsjah, \& Elidjen. (2018), "The Role of Distinctive Organisational Capability in Formulating Co-Creation Strategy and Business Model Innovation", Polish Journal of Management Studies, 18(2), 197-208.

[39] Mikalef, P., \& Pateli, A. (2017), " Information technology-enabled dynamic capabilities and their indirect effect on competitive performance: Findings from PLS-SEM and fsQCA", Journal of Business Research, 70, 1-16.

[40] Nasir, M., Mohamad, M., Ghani, N., \& Afthanorhan, A. (2020). Testing mediation roles of place attachment and tourist satisfaction on destination attractiveness and destination loyalty relationship using phantom approach. Management Science Letters, 10(2), 443-454.

[41] Nordin, N. (2012), "The influence of leadership behavior and organizational commitment on organizational readiness for change in a higher learning institution", Asia Pacific Education Review, 13(2), 239-249.

[42] Nwaiwu, F. (2018), "Review and Comparison of Conceptual Frameworks on Digital Business Transformation", Journal of Competitiveness, 10(3), 86-100.

[43] Nwankpa, J. K., \& Roumani, Y. (2016), " IT Capability and Digital Transformation: A Firm Performance Perspective", Thirty Seventh International Conference on Information Systems, Dublin 2016 . 1-16.

[44] Oliveira, T and Martins, M, F, (2011), "Literature Review of Information Technology Adoption Models at Firm Level" The Electronic Journal Information Systems Evaluation Volume 14 Issue 1, pp110- 121.

[45] Oke, A., Munshi, N., \& Walumbwa, F. O. (2009), "The Influence of Leadership on Innovation Processes and Activities", Organizational Dynamics, Vol. 38 No. 1, 64-72.

[46] Onyeji-Nwogu, Morgan Bazilian, and Todd Moss. (2017), "Challenges and Solutions for the Electricity Sector in African Markets." CGD Policy Paper. Washington, DC: Center for Global Development.

[47] Orji, c. I. (2019), "Digital business transformation: towards an integrated capability framework for digitization and business value generation. Journal of global business and technology; huntington station vol. 15, 1, 47-57.

[48] Osmundsen, K. (2018), "Competences for Digital Transformation: Insights from the Norwegian Energy Sector", Hawaii International Conference on System Sciences.

[49] Parida, V., Oghazi, P., \& Cedergren, S. (2016), "A study of how ICT capabilities can influence dynamic capabilities", Journal of Enterprise Information Management, 29(2), 179-201.

[50] Pavlou, P. A., \& El Sawy, O. A. (2011). Understanding the Elusive Black Box of Dynamic Capabilities: The Elusive Black Box of Dynamic Capabilities. Decision Sciences, 42(1), 239273.

[51] Pérez López, S., Manuel Montes Peón, J., \& José Vázquez Ordás, C. (2004). Managing knowledge: The link between culture and organizational learning. Journal of Knowledge Management, 8(6), 93-104

[52] Porter, M. E., \& Heppelmann, J. E., (2014)", "How Smart, Connected Products Are Transforming Competition" https://hbr.org/2014/11/how-smart-connected-products-aretransforming-competition, accessed on 26/6/2020.

[53] Relly, M., Sharkey Scott, P.: Subsidiaries, (2009), "Competencies and the Implementation of Dynamic Capabilities", Irish Academy of Management Conference, NUI Galway.

[54] David Rogers. (2016), "The digital transformation playbook: rethink your business", Columbia University Press. 
[55] Saá-Pérez, P. D., \& García-FalcÓn, J. M. (2002), "A resource-based view of human resource management and organizational capabilities development", The International Journal of Human Resource Management, 13(1), 123-140.

[56] Sanchez, M. A. (2017), "Framework to assess organizational readiness for digital transformation", Dimensión Empresarial, 15(2).

[57] Schumacher, A., Erol, S., \& Sihn, W. (2016). A Maturity Model for Assessing Industry 4.0 Readiness and Maturity of Manufacturing Enterprises. Procedia CIRP, 52, 161-166.

[58] Shin, J., Taylor, M. S., \& Seo, M.-G. (2012), "Resources for Change: The Relationships of Organizational Inducements and Psychological Resilience to Employees' Attitudes and Behaviors toward Organizational Change", Academy of Management Journal, 55(3), 727-748.

[59] Sow, M., \& Aborbie, S. (2018), " Impact of Leadership on Digital Transformation", Business and Economic Research, 8(3), 139.

[60] Stewart et al, (2016), "Phantom Ex Machina: Digital Disruption's Role in Business Model

[61] Stogdill, R. M. (1974), "Handbook of leadership: A survey of theory and research", Free Press Transformation. Springer International Publishing Switzerland 2017.P3-21

[62] Sun et al., (2018), "Understanding the Factors Affecting the Organizational Adoption of Big Data", Journal of Computer Information Systems, 58(3),

[63] Teece, D. J., Pisano, G., \& Shuen, A. (1997), "Dynamic Capabilities and Strategic Management", strategic Management Journal, Vol. 18:7, 509-533 .

[64] Toduk Y., Gande S., 2016, What's Next In Turkey? A New Leadership Model for Connected Age, Amrop Leadership Series.

[65] Vogelsang, K., Liere-Netheler, K., Packmohr, S., \& Hoppe, U. (2019), " Success factors for fostering a digital transformation in manufacturing companies", Journal of Enterprise Transformation, 1-22.

[66] W Wasono, L., \& Furinto, A. (2018), "The effect of digital leadership and innovation management for incumbent telecommunication company in the digital disruptive era", International Journal of Engineering \& Technology, 7(2.29), 125.

[67] Wade \& Hulland. (2004), "Review: The Resource-Based View and Information Systems Research: Review, Extension, and Suggestions for Future Research", MIS Quarterly, 28(1), 107.

[68] Wade, M., Piccoli, G. and Ives, B. (2011) 'IT-dependent strategic initiatives and sustained competitive advantage: a review, synthesis, and an extension of the literature', in Currie, W.L. and Galliers, R.D. (Eds.): The Oxford Handbook of Management Information Systems: Critical Perspectives and New Directions, pp.1-32, Oxford University Press, Oxford, England.

[69] Wahyu Wasono Mihardjo, L., \& Sasmoko, S. (2019), "Digital Transformation: Digital Leadership Role in Developing Business Model Innovation Mediated by Co-Creation Strategy for Telecommunication Incumbent Firms", In Strategy and Behaviors in the Digital Economy. IntechOpen.

[70] Weiner, B. J. (2009), "A theory of organizational readiness for change", Implementation Science, 4(1), 67.

[71] Westerman, Bonnet And Mcafee, (2014), "Leading Digital Turning Technology Into Business Transformation", Harvard Business Review Press. Boston, Massachusetts

[72] Winter, S. G. 2003. Understanding dynamic capabilities. Strategic Management Journal 24(10): 991-995

[73] Wu, L.-Y. (2010), "Applicability of the resource-based and dynamic-capability views under environmental volatility". Journal of Business Research, 63(1), 27-31. 
[74] Yukl, G. A. (2013)., "Leadership in organizations", Pearson, (8th ed).

[75] Zaidi, M. F. A., \& Othman, S. N. (2012), "Understanding the Concept of Dynamic Capabilities by Dismantling Teece, Pisano, and Shuen (1997)'s Definition", International Journal of Academic Research in Business and Social Sciences, 2(8), 1-12.

[76] Zhang, \& Li. (2016). Organizational culture and organizational performance: A brief review. Journal of Advances in Social Science and Humanities, 2(5). 